\title{
Experience with congruity in the perception of incongruity
}

WILLIAM J. LASKO, JR. AND MARTIN S. LINDAUER, DEPARTMENT OF PSYCHOLOGY, STATE UNIVERSITY OF NEW YORK, COLLEGE AT BROCKPORT, N. Y.

The recognition thresholds for the perception of a trick card were higher than that of normal cards. Sensitivity to the incongruous item was not influenced by the amount of congruous information, whether manipulated prior to, or during the experiment. It was concluded that differential degrees of congruent experience does not affect the perception of incongruity when the critical material is already highly familiar.

The perception of incongruity has been shown by Bruner $\&$ Postman (1949) to be related to the amount of experience with incongruous, but not congruous material (although recognition thresholds for the latter, irrespective of the amount of congruous experience, were higher than that of congruous material). The positioning of a trick playing card (i.e., color and suit reversed) at various points within a series of normal playing cards, thereby exposing the incongruous card to differing degrees of congruous information, did not lead to differential recognition thresholds. The effect of congruous experience on the recognition of congruity was re-examined in the present experiment by increasing the amount of congruent information available prior to the critical series containing the incongruous item. It was hypothesized that as the degree of both external (pre-experimental) and internal (intra-experimental) congruous experience increased, the recognition threshold for incongruous material would also increase. It was reasoned that a set or expectation for congruity would be strengthened by increasing the exposure to congruous items, thereby making it more difficult to notice incongruous material. Method

Forty-five volunteer Ss were randomly assigned into three equal groups, in which a combination of various external and internal sources of congruent information was presented. The three external (pre-experimental) conditions were: "congruous" (a deck of normal playing cards sorted once according to color and suit); "irrelevant" (monopoly cards sorted by categories); and "none" (no pre-experimental experience). (The "irrelevant" condition not only served as a control for task warm-up, but by drawing Ss' attention to color also provided a partially relevant congruent set for the experimental series.) Ss were then immediately presented with one of three internal (intra-experimental) conditions in which a trick card (the-four-of-hearts-in-black) was embedded in a

Table 1

Mean Recognition (in meec) for Normal and Trick Cards

\begin{tabular}{|c|c|c|c|c|c|c|}
\hline \multicolumn{7}{|c|}{ Pre-Experimental Conditions } \\
\hline $\begin{array}{l}\text { Cards } \\
\text { Normal }\end{array}$ & $\begin{array}{c}\text { Congruous } \\
95.83\end{array}$ & $\begin{array}{c}\text { Irrelevant } \\
93.00\end{array}$ & $\begin{array}{l}\text { None } \\
95.33\end{array}$ & \multicolumn{3}{|c|}{$\begin{array}{l}\text { Total } \\
\mathbf{9 4 . 7 2}\end{array}$} \\
\hline \multicolumn{7}{|l|}{ Trick } \\
\hline All positions & 493.33 & 443.33 & 443.33 & \multicolumn{3}{|c|}{460.00} \\
\hline Beginning & \multicolumn{2}{|c|}{360.00} & 400.00 & 380.00 & & 380.00 \\
\hline Middle & 555. & & & 510.00 & & 536.67 \\
\hline End & 570. & & & 440.00 & & 463.33 \\
\hline
\end{tabular}

random series of four normal playing cards (a five-of-hearts, ace-of-hearts, five-of-spades, and seven-of-spades). The incongruous card was placed at either the beginning, middle, or end positions of the series, thereby varying the amount of internal congruent experience from minimum to maximum, respectively. Each card was shown tachistoscopically three times in succession at speeds which regularly increased from $10-1000 \mathrm{msec}$, until the card was correctly reported and reproduced (colored crayons and blank paper were provided) twice in succession. Except for the addition of two external conditions (and the reproduction criterion of correct recognition), the design, procedures, and materials were the same as those used in this aspect of the original Bruner and Postman study.

Results

The recognition times for the four normal cards, whose means ranged from 84-108 msec, were not significantly different from each other $(F<1)$ and were therefore combined in the analysis. Table 1 presents all the data of the experiment. The results of the three pre-experimental conditions, in which the recognition means of the normal cards differed by less than $3 \mathrm{msec}$ from each other $(F<1)$, indicated that exposure to external sources of congruent information was ineffective in changing recognition thresholds. With respect to the role of congruent experience within the experiment, recognition times did not significantly differ as a function of the incongruous card's position at the beginning, middle, or end of the series of normal cards $(F=2.25, \mathrm{df}=2 / 42, \mathrm{p}$ $>.05)$. What does seem evident is the great difference in recognition times between normal and trick cards in general $(t=$ $6.57, \mathrm{df}=44, \mathrm{p}<.01)$ and at each pre-experimental condition $(\mathrm{t}=$ $6.04-8.98$, df $=14, p<.01$ ): The incongruous card took about five times longer to be recognized than congruous cards did.

Discussion

Although incongruous material was consistently recognized later than congruous material, this reaction was insensitive to the absence or presence of various degrees of prior external and internal congruous information. The combination of conditions which led to the greatest amount of congruous experience (the congruous pre-experimental task; the trick card positioned at the end of the series) was no different in its effect on the recognition of incongruity than those conditions which incorporated the least amount of congruous experience (no pre-experimental task; the trick card at the beginning of the series). These results may be due to the experiment's inability to actually minimize or vary different levels of past experience with playing cards. Since most Ss have already had substantial experience with such materials prior to the experiment, congruous experience was already maximized and therefore could not be affected by the various experimental treatments. Hence the lack of differential recognition for incongruity as a function of differential exposures to congruent information. Because experience with incongruous playing cards is nonexistent, this accounts for Bruner and Postman's finding that the perception of incongruity is experimentally susceptible to different degrees of exposure to incongruous material.

\section{REFERENCE}

BRUNER, J. S., \& POSTMAN, L. On the perception of incongruity: A paradigm. J. Pers., 1949, 18, $206-223$. 